
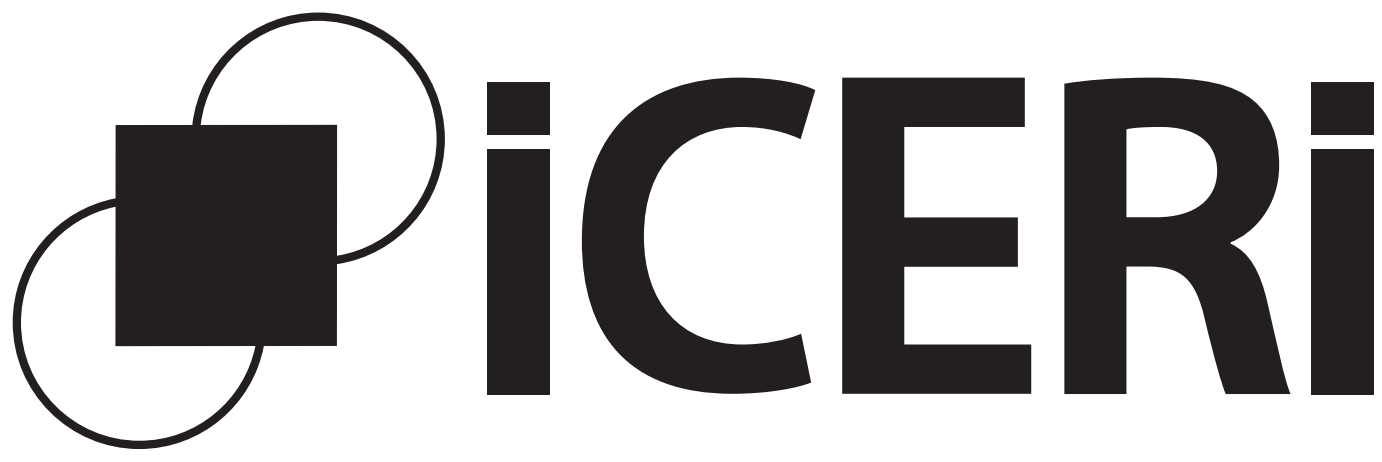

2020

13TH INTERNATIONAL CONFERENCE OF EDUCATION,

RESEARCH AND

INNOVATION
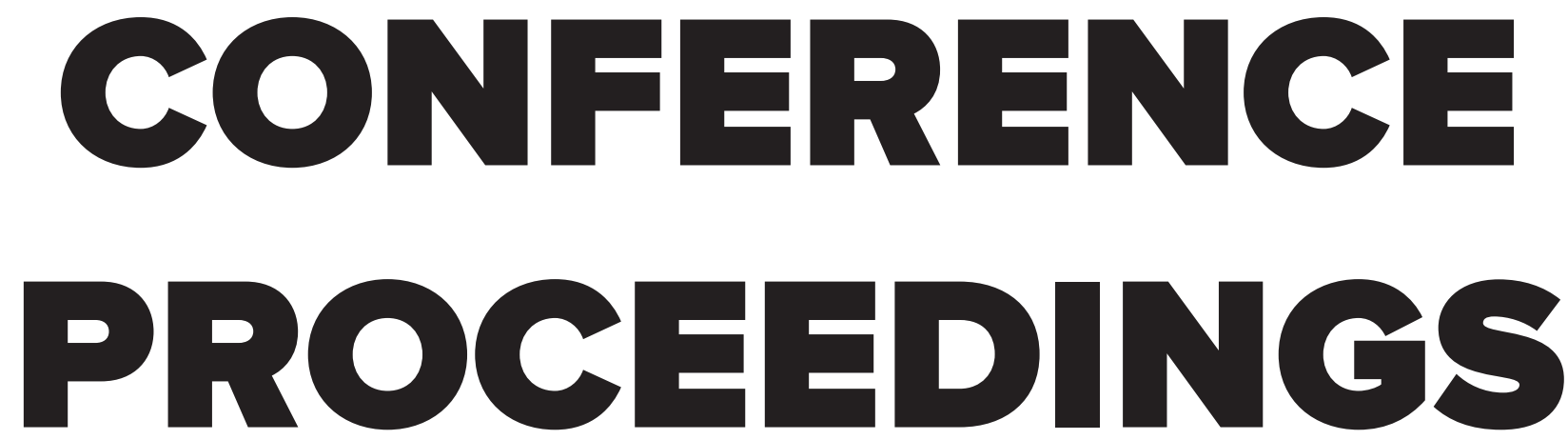

9-10 NOVEMBER 2020 iated.org/iceri 
Published by

IATED Academy

iated.org

\section{ICERI2020 Proceedings}

13th International Conference of Education, Research and Innovation

November 9th-10th, 2020

\section{Edited by}

L. Gómez Chova, A. López Martínez, I. Candel Torres

IATED Academy

ISBN: 978-84-09-24232-0

ISSN: $2340-1095$

V- 2372-2020

Book cover designed by

J.L. Bernat

All rights reserved. Copyright (C) 2020, IATED

The papers published in these proceedings reflect the views only of the authors. The publisher cannot be held responsible for the validity or use of the information therein contained. 


\title{
ENTREPRENEURSHIP TRAINING COURSE FOR MENTORS AND PUPILS: A MOOC EXPERIENCE IN HEI AND BUSINESS
}

\author{
M. Potes ${ }^{1}$, R. Pedro' , S. Leal' ${ }^{1}$ M. José ${ }^{1}$, G. Kalamata ${ }^{3}$, D. Vukovic ${ }^{4}$ \\ ${ }^{1}$ Instituto Politécnico Santarém (PORTUGAL) \\ ${ }^{2}$ Nersant (PORTUGAL) \\ ${ }^{3}$ Center for Social Innovation (CYPRUS) \\ ${ }^{4}$ Croatian Down Syndrome Association (CROATIA)
}

\begin{abstract}
This work is being carried out in the context of the project 'Starting Up - Accelerators of Entrepreneurship 4 Inclusion' and it aims, among other things, at the development of an Entrepreneurship Training Course for Mentors and Pupils, following a Massive Open Online Course (MOOC) approach. The target group of this MOOC is pupils with Intellectual and Developmental Difficulties (IDD pupils), as well as their mentors.

The MOOC was developed according to the needs of pupils with IDD. In order to create a strong and sustainable course, the following steps were implemented: (a) the identification and creation of tools for mentors who work with this population; (b) the development of interactive and visual contents to increase students' motivation; (c) the study of the needs of the labour market were the pupils will be workers or entrepreneurs; (d) the development of contents that helps to strengthen labour skills, both for employment and self-employment.
\end{abstract}

The course was developed in an innovative and enhanced way, using various multimedia content (texts, images, audios, and videos) as well as using the best practices of accessibility and usability (e.g., HTML5). The MOOC approach ensures an easy way for pupils to access and use the platform, but also increases the transferability of the contents.

The MOOC is organized into two sections. The first section is a course for mentors. It aims to develop mentors' skills and competencies to teach IDD pupils and give them support in employment and selfemployment processes. Some other topics included are the preparation of the mentors to promote the inclusion of people with disabilities in the labour market, and the challenges and opportunities of employability in digital environments. The second section was designed for IDD pupils and is organized in two main topics: (a) the development of pupils' skills in order for them to create a winner profile, with contents including: how to create an e-portfolio, how to prepare an interview, sharing of good practices, connecting with job platforms etc. and (b) the promotion of a successful life in the labour market, namely through employment, self-employment, and sharing of success cases.

To assess the contents of the MOOC, two surveys were implemented. The first was applied to future possible tutors. They were trained professors in the field of education. These professors analyzed the MOOC contents and structure and provided feedback to improve it. The second survey was applied to ten IDD pupils, after testing the platform contents. The feedback of each public was used to improve the MOOC.

The MOOC is an open access platform and a free tool to promote the employment and self-employment of IDD pupils. Future tests will be made with real tutors and IDD pupils.

Keywords: Pupils with Intellectual and Developmental Difficulties (IDD), Massive Open Online Course (MOOC), employment, self-employment.

\section{INTRODUCTION}

The development of competences and the subsequent integration of young people into the labour market are two of the main objectives of the Higher Education Institutions (HEls) in general. These objectives need to be extended to other types of the public that usually do not develop skills in HEls, namely young people with Intellectual and Developmental Difficulties (IDD). HEls can take advantage of the existing know-how concerning the development of job search and job creation skills/entrepreneurship skills, usually designed for young students, to provide young people with IDD with the same skills, after the appropriate changes to the profile of these candidates. At present, there 
are few initiatives aimed at integrating young people with IDD in the labour market. The "Starting Up Accelerators Of Entrepreneurship 4 Inclusion" project aims, precisely, among other aspects, to create an online course for the development of job search, job creation, and entrepreneurship skills adjusted to the profile and needs of young people with IDD. It will be accomplished by the development of an Entrepreneurship Training Course for Mentors and Pupils, following a Massive Open Online Course (MOOC) approach. The target group of this MOOC is pupils with IDD (IDD pupils), as well as their mentors. This paper aims to present the MOOC developed in the context of the Starting Up project, as well as the results of its evaluation to future users, in particular IDD users. Section 2 presents the MOOC developed. The contents and usefulness of the MOOC were tested by possible future users: tutors and pupils. The results of these tests will be reported in section 3 (methodology) and 4 (results). Then, we present the main conclusions (section 5).

\section{THE MOOC}

MOOCs are "online courses designed for large numbers of participants, that can be accessed by anyone anywhere as long as they have an internet connection, are open to everyone without entry qualifications, and offer a full/complete course experience online for free" [1]. This definition approach a MOOC as having four dimensions (each dimension represented by a letter of the acronym) [1]: $\mathrm{M}$ - Massive, $\mathrm{O}-$ Open, $\mathrm{O}$ - Online, $\mathrm{C}-$ Course. MOOCs have attracted much attention as a way to expand higher education opportunities and improve the quality of instruction and learning [2]. The MOOCs allow the HEls to provide course materials such as videos, readings, and problem sets, as well as interactive user forums that help build a community for students and professors [3]. But the success of MOOCs depends on learners' continued usage and it is influenced by several factors, such as system quality, course quality, and service quality [3]. Besides, it was discovered that the effect of course quality and service quality on continuance intention of students toward participation in MOOCs were mediated by perceived usefulness [3]. The MOOC developed in the Starting Up project took into consideration such concerns.

The MOOC was developed according to the needs of pupils with IDD. To create a strong and sustainable course, the following steps were implemented: (a) the identification and creation of tools for mentors that work with this population; (b) the development of interactive and visual contents to increase students' motivation; (c) the study of the needs of the labour market were the pupils will be workers or entrepreneurs; (d) the development of contents that help to strengthen labour skills, both for employment and self-employment.

The course was developed in an innovative and enhanced way, using various multimedia contents (texts, images, audios, and videos) as well as using the best practices of accessibility and usability (e.g., HTML5). The MOOC approach ensures an easy way for pupils to access and use the platform but also increases the reuse of the contents.

The MOOC is organized into two sections. The first section is a course for mentors. It aims to develop mentors' skills and competencies to teach IDD pupils and give them support in employment and selfemployment areas. Some other topics included are the preparation of the mentors to promote the inclusion of people with disabilities in the labour market, and the challenges and opportunities of employability in digital environments. The second section was designed for IDD pupils and it is organized in two main topics: (a) the development of pupils' skills for them to create a winner profile, with contents including how to create an e-portfolio, how to prepare an interview, sharing of good practices, connecting with job platforms, etc. and (b) the promotion of a successful life in the labour market, namely through employment, self-employment, and sharing of success cases. All the contents were developed taking into consideration the best international practices in the IDD area, namely from the International Labour Office [4], The Conference Board of Canada [5], European Commission [6].

\section{METHODOLOGY}

To assess the contents of the MOOC, two surveys were implemented. The first was applied to eleven future possible tutors ( $36 \%$ male, $64 \%$ female). They were trained professors in the field of education. These professors analyzed the MOOC contents and structure and provided feedback to improve it.

The second survey was applied to ten IDD pupils. From the IDD pupils: (a) one was male $(10 \%)$ and nine females (90\%); (b) five (50\%) have between 18 and 22 years old, four ( $40 \%$ ) have between 23 and 26 years old, and one (10\%) has between 27 and 30 years old. All the pupils were students of the "Digital Literacy for Labour Market" course from Instituto Politécnico de Santarém. This survey was divided into three parts: (1) initial questions about the MOOCs in general; (2) focus group, with open questions, in 
groups of three or four pupils to analyse and assess specific parts of the MOOC; (3) final assessment of the experience they had with the MOOC.

The results of both surveys are presented in the next section. The feedback of each public was used to improve the MOOC.

\section{RESULTS}

This section presents the results of the surveys built to assess the first draft of the MOOC developed. The first survey was applied to mentors, and the second to IDD pupils.

\subsection{Mentors assessment of MOOC}

The first two questions to mentors were related to their availability to participate in a MOOC (Table 1). About $81 \%$ of the mentors are available to participate in a MOOC about welcoming people with disabilities in the labour market. However, only $53 \%$ were available to give support on the forum of discussion activities during the lifecycle of the MOOC.

Table 1. Availability of mentors to collaborate in the MOOC

\begin{tabular}{l|c|c|c}
\hline \hline & Yes & Maybe & No \\
\hline $\begin{array}{l}\text { Would you like to participate in a MOOC about welcoming people with disabilities in } \\
\text { labour market? }\end{array}$ & $81 \%$ & $19 \%$ & $0 \%$ \\
\hline $\begin{array}{l}\text { Are you with availability to give support on the forum of discussion activities during the } \\
\text { lifecycle of the MOOC? }\end{array}$ & $53 \%$ & $47 \%$ & $0 \%$ \\
\hline \hline
\end{tabular}

Then, the mentors were invited to use the MOOC, to experience it as future mentors, and subsequently, to assess it (Figure 1). Most of the respondents agree or absolutely agree that the course was well structured to achieve the learning objectives, that the MOOC facilitated the communication and learning process, and that the interaction with pupils in the forum discussion was important to clarify their doubts. However, in what concerns to the use of MOOC by pupils to ask questions or doubts, the more common answer was "neither agree nor disagree".

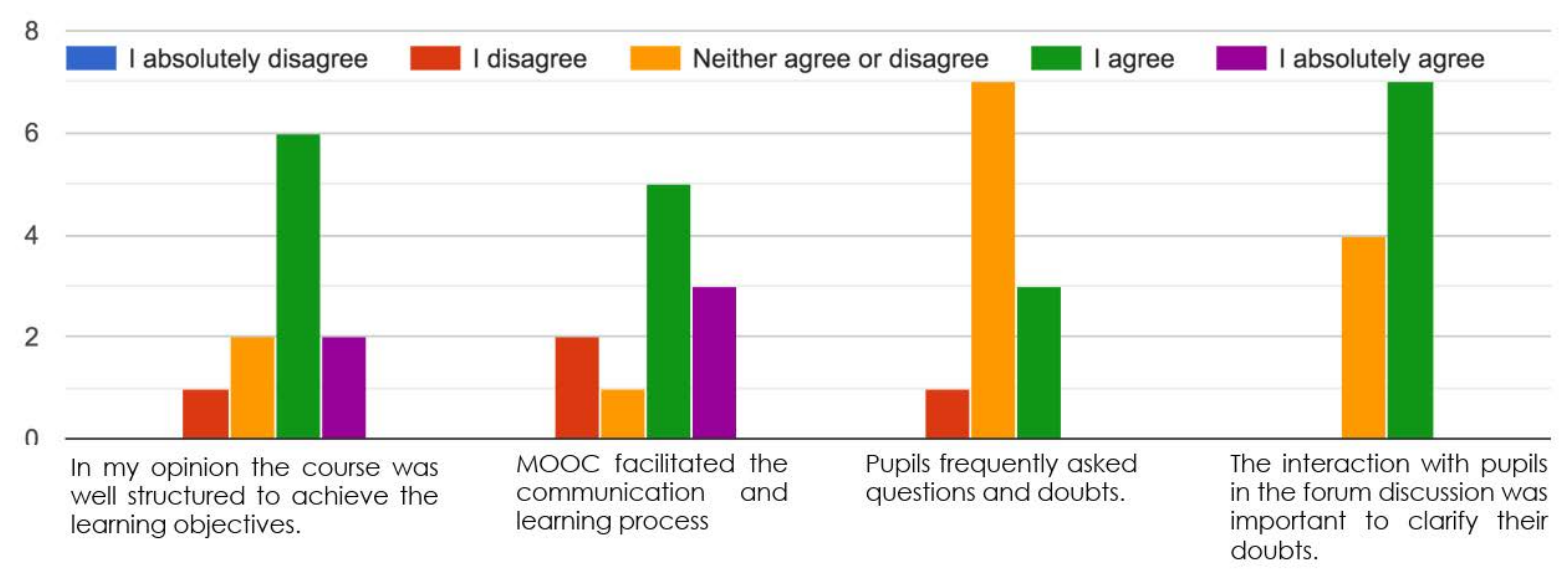

Figure 1. MOOC's evaluation.

Next, tutors were invited to assess the MOOC's resources and activities (Figure 2). Most of the tutors agree or absolutely agree that: the available resources (e.g., documents, videos, presentations, links) were useful, the concepts were presented with clarity, the proposed activities were appropriate to their professional context, the course stimulated their interest and reflection on the topics, and the timing was appropriate. 


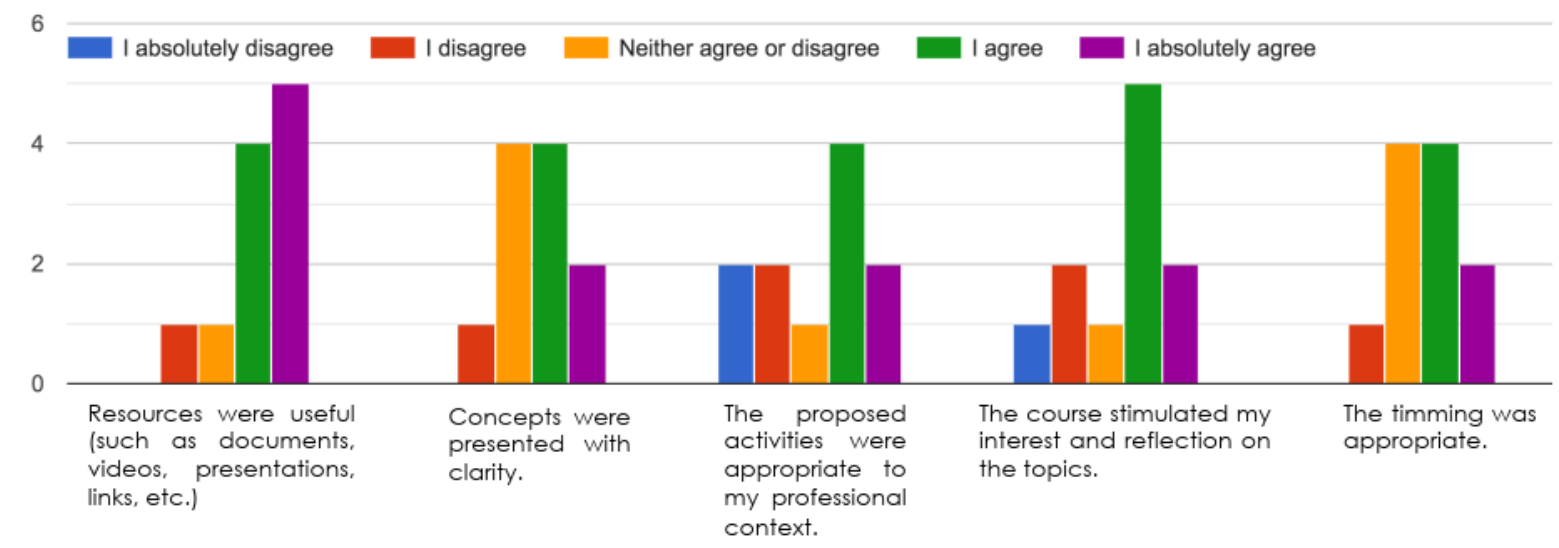

Figure 2. MOOC's resources and activities.

\subsection{Pupils assessment of MOOC}

First, the ten pupils were questioned if they knew what a MOOC is. About $70 \%$ did not know what a $\mathrm{MOOC}$ is ( $30 \% \mathrm{knew}$ what it is). From the three that mentioned that knew what it is, just one was able to explain the meaning of a MOOC. Then, they were asked if they would like to hold a MOOC on entry into the labour market, where $70 \%$ answered yes and $30 \%$ maybe. The time they would be willing to carry out the MOOC was the next question. The answers have a high dispersion: $20 \%$ will spend one to three days with the MOOC; $10 \%$, about three to five days; $40 \%$, five to seven days; $10 \%$, seven to nine days; $20 \%$, between thirteen and fifteen days. They also mentioned, in an open question, what contents would like to see covered in the MOOC related to the labour market. The most frequent answers were curriculum vitae, job interview, and tips for finding adapted jobs.

Then, the pupils were organized into three groups of three or four elements to explore the contents of the MOOC developed. The pupils were organized by three areas (from different sections of MOOC): (a) Welcome, E-Portfolio and Be prepared to present yourself in an interview; (b) Sharing good practices; (c) Employment, Self-employment and Success Cases. After adequate amount of time, granted to explore the MOOC contents, the pupils gave feedback about it and reported the difficulties they felt. In table 2 , it is presented a resume of the feedback and main difficulties.

Table 2. Availability of mentors to collaborate in the MOOC

\begin{tabular}{l|l}
\hline \hline \multicolumn{1}{c|}{ MOOC section } & \multicolumn{1}{c}{ Feedback } \\
\hline $\begin{array}{l}\text { Welcome, E-Portfolio and Be } \\
\text { prepared to present yourself in an } \\
\text { interview }\end{array}$ & $\begin{array}{l}\text { - After preparing the CV, the platform does not provide a way to load the } \\
\text { E-portfolio into the MOOC. } \\
\text { - "It was nice and interesting and important for labour market". }\end{array}$ \\
\hline Sharing good practices & $\begin{array}{l}\text { - The topic could have games. } \\
\text { - "The first video was extraordinary. The second video was very striking } \\
\text { in the part of the employee having trisomy 21 (...)". }\end{array}$ \\
\hline $\begin{array}{l}\text { Employment, Self-employment, and } \\
\text { Success Cases }\end{array}$ & Noting to mention. \\
\hline \hline
\end{tabular}

At the end, a final questionnaire was applied to the pupils for a global assessment of the experience they had with the MOOC. One hundred percent liked the MOOC performance. When asked about what they did most liked to learn (open question), the more relevant answers were: (a) All; (b) I liked to work on the MOOC, it is important for our internship; (c) The informatic part. In turn, when asked about what they would change about the MOOC, the more relevant answers were: (a) I would not change anything/Nothing; (b) Have more games. When questioned about the time they would take to complete the MOOC, the majority will take one week (Figure 3 ). In the last question, the pupils assessed the MOOC with a Likert scale (1: Easy; 2: Moderate; 3: Challenger; 4: Difficult; 5 : Very Difficult). $37.5 \%$ feel that the MOOC was easy, $12.5 \%$ moderate, $12.5 \%$ challenger, and $37.5 \%$ very difficult. 


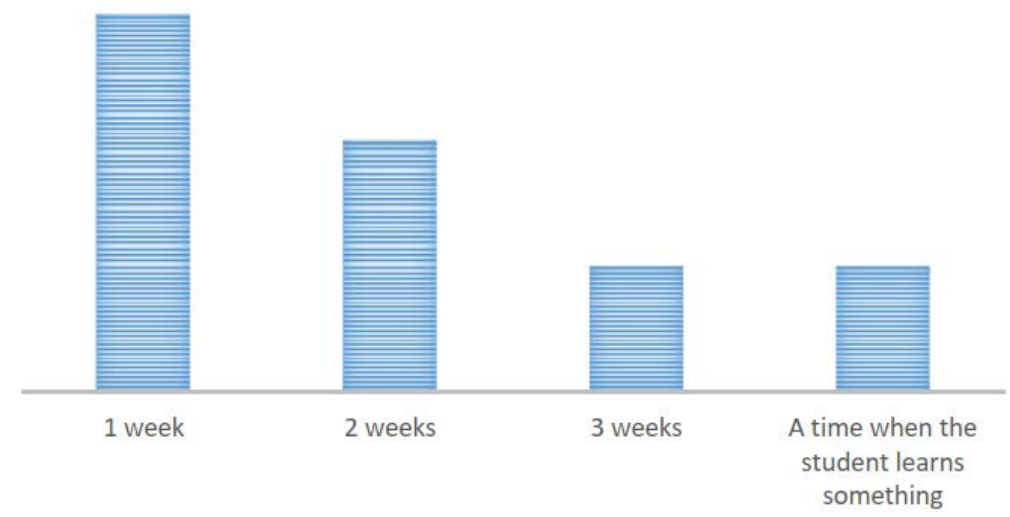

Figure 3. How long do you think it would take you to complete the MOOC?

\section{CONCLUSIONS}

This article presents a MOOC built for the development of entrepreneurship skills, as well as job search and job creation skills, adapted to IDD pupils. The experience of $\mathrm{HEl}$, where the MOOC was developed, both in e-learning and in the training of young people with IDD, was determinant for the development and testing of the MOOC. The MOOC has two major sections, one aimed at IDD pupils and the other at future trainers or teachers in the area. Taking into account the importance of measuring system quality, course quality, and service quality to ensure the continuation of the MOOC by users [3], two surveys were developed, one applied to tutors/teachers, and the other to pupils. The results of the surveys were used to improve the system quality, course quality, and service quality of the MOOC.

\section{ACKNOWLEDGEMENTS}

Study funded by the Erasmus+ project 'STARTING UP - ACCELERATORS OF ENTREPRENEURSHIP 4 INCLUSION' (Project Reference: 2019-1-PT02-KA205-005995).

\section{REFERENCES}

[1] D. Jansen; R. Schuwer, "Institutional MOOC strategies in Europe: Status report based on a mapping survey conducted in October - December 2014". 2015. Retrieved from https://www.researchgate.net/profile/Darco_Jansen/publication/286925234_Institutional_MOOC_s trategies_in_Europe_Status_report_based_on_a_mapping_survey_conducted_in_October__December_2014/links/56700bf008ae4d9a42598cb1/Institutional-MOOC-strategies-in-EuropeStatus-report-based-on-a-mapping-survey-conducted-in-October-December-2014.pdf

[2] Y. Jung; J. Lee, "Learning Engagement and Persistence in Massive Open Online Courses (MOOCS)", Computers \& Education, vol. 122, pp. 9-22, 2018. doi:https://doi.org/10.1016/j.compedu.2018.02.013

[3] M. Yang; Z. Shao; Q. Liu \& C. Liu, "Understanding the quality factors that influence the continuance intention of students toward participation in MOOCs", Educational Technology Research \& Development, vol. 65, n. 5, pp. 1195-1214, 2017. doi:10.1007/s11423-017-9513-6

[4] International Labour Office, Inclusion of People with Disabilities in Vocational Training: A Practical Guide. Geneva, 2013.

[5] The Conference Board of Canada, Employers' Toolkit: Making Ontario Workplaces Accessible to People with Disabilities ( $2^{\text {nd }}$ ed.). Ontario, 2015.

[6] European Commission, The Changing Nature of Work and Skills in the Digital Age. Brussels, 2019. 